$9-2021$

\title{
Employee Satisfaction and Stock Returns During the COVID-19
} Pandemic

Mary J. Becker

Alexander Cardazzi

Zachary McGurk

Follow this and additional works at: https://researchrepository.wvu.edu/econ_working-papers

Part of the Economics Commons 


\title{
Employee satisfaction and stock returns during the COVID-19 Pandemic
}

\author{
Mary Becker* \\ Canisius College
}

\author{
Alexander Cardazzi ${ }^{\dagger}$ \\ West Virginia University
}

September 23, 2021

\author{
Zachary McGurk ${ }^{\ddagger}$ \\ Canisius College
}

\begin{abstract}
The COVID-19 Pandemic has had an unprecedented impact on how employees and employers operate. Employees, directly affected by workplace changes, may provide information regarding future efficiencies. As a result, crowdsourced employee satisfaction $(E S)$ reviews mentioning the COVID-19 Pandemic may contain useful information regarding the future profitability of these firms. We utilize crowdsourced COVID-19 Pandemic specific ES obtained from Glassdoor.com to determine the impact on abnormal stock returns for public firms from March-December 2020. We find evidence that higher COVID-19 ES is related to higher abnormal stock returns. While non-COVID $E S$ is found not to be related to abnormal stock returns.
\end{abstract}

JEL Codes: G12,G41,G39

Keywords: COVID-19 Pandemic, Glassdoor, Employee Satisfaction, Abnormal Returns.

\section{Introduction}

Due to the inside nature of their positions, employees may possess nonpublic information which is valuable to investors, especially during times of high uncertainty like the COVID-19 Pandemic (Au et al. (2021); Chemmanur et al. (2019); Green et al. (2019); and Ylinen and

*Department of Economics and Finance, Wehle School of Business Canisius College, 2001 Main St, Buffalo, NY 14208, Phone:(716) 888-2676, Email: becker30@canisius.edu.

†'Department of Economics, John Chambers College of Business \& Economics, West Virginia University, 1601 University Ave., PO Box 6025, Morgantown, WV 26506, Phone: (304) 293-4092, email: ajc0056@mix.wvu.edu

${ }^{\dagger}$ Corresponding Author: Department of Economics and Finance, Wehle School of Business, Canisius College, 2001 Main St., Buffalo, NY 14208, Phone: (716) 888-2786, Email: mcgurkz@canisius.edu. 
Ranta (2021)). The COVID-19 Pandemic and resulting lockdowns disrupted company operations globally, leading to changes that were particularly acute for employees. Firms were forced to make massive changes to how employees worked; some offered remote employment, others engaged in massive layoffs, and still others increased hiring 1 . To all of these operational fluctuations employees have had a unique perspective in determining if these changes led to gains or loss in efficiency, thus generating information regarding future profitability. As a result, employee satisfaction reviews mentioning the COVID-19 Pandemic may contain useful information for investors.

Disruption from the pandemic resulted in the largest month to month increase in the US unemployment rate in the post-WWII period and the highest level of unemployment over the same period increasing from 3.5\% in February 2020 to $14.7 \%$ in April 2020. 2 As a result, current and former employees may have had more time and willingness to provide accurate nonpublic information regarding their satisfaction and the operation of their firm. Consequently, the COVID-19 Pandemic offers a unique framework to study the impact of employee satisfaction on firm returns.

Our investigation relies on information provided by crowdsourced employee reviews from Glassdoor.com (Glassdoor). Glassdoor is a website where current and former employees assign a star rating and provide textual descriptions of their employers in a style similar to Yelp restaurant reviews. For example, Glassdoor asks reviewers to provide information on the corporate culture, work environment, career opportunities, and even future company outlook. The reviews are applied to the company as a whole and those looking for employment can inspect company ratings to determine if a particular employer would be a suitable one.

We use employee reviews from Glassdoor to test whether public companies with higher employee-given satisfaction ratings regarding the COVID-19 Pandemic experience are related to the cross section of abnormal stock returns. Using a sample of Glassdoor reviews for the period March 15, 2020 to December 31, 2020, we find evidence that positive employee satisfaction mentioning the COVID-19 Pandemic are associated with positive abnormal stock returns. While we find no such association for employee satisfaction over this period that are not identified as relating specifically to the COVID-19 Pandemic.

Similar to the COVID-19 Pandemic, the 2008-2009 Global Financial Crisis brought upheaval to companies and their employment practices. Research using data from this period suggests that when experiencing economy-wide shocks, firms with more satisfied employ-

\footnotetext{
${ }^{1}$ See Bureau of Labor Statistics Effects of COVID-19 Pandemic on the Employment Situation News Release and Data https://www.bls.gov/COVID19/effects-of-COVID-19-pandemic-and-response-onthe-employment-situation-news-release.htm

${ }^{2}$ Source: Congressional Research Service Report on Unemployment Rates During the COVID-19 Pandemic, updated May 20, 2021. https://fas.org/sgp/crs/misc/R46554.pdf
} 
ees performed better than firms with less employee-friendly cultures (Fauver et al. (2018)). This performance may be tied to labor efficiencies, innovation, or employee flexibility. For example, Cao and Rees (2020) found that companies with employee-friendly cultures engaged in less efficient labor investments during the crisis but more efficient investments in the long run. Further, evidence from Chen et al. (2016b) suggests that employee-friendly firms achieved greater innovative success and were more likely to sustain R\&D investment during the Global Financial Crisis. Au et al. (2021) use employee ratings from Indeed.com, an online job board and employer review website, and find that firms offering more employee flexibility performed better during the 2008-2009 Global Financial Crisis. Additionally, Lins et al. (2017) find that firms with high corporate social responsibility, of which employee satisfaction is a part, had higher stock returns than firms with low social capital during the same period.

The relationship between workplace satisfaction and stock valuation has attracted substantial attention from scholars (Chemmanur et al. (2019); Edmans (2011); Faleye and Trahan (2011); Fauver et al. (2018); Green et al. (2019); Ylinen and Ranta (2021)). In early work, Edmans (2011) and Faleye and Trahan (2011) examine companies listed in Fortune's "Best 100 Companies to Work for in America" and find a positive relationship between being included on the list and shareholder returns. Using employee ratings found on Glassdoor, Green et al. (2019) find that increases in employee satisfaction are associated with higher positive stock returns. Additionally, companies considered employee friendly by an outside agency experience more positive earnings surprises Edmans (2011), higher ROA and Tobin's Q Fauver et al. (2018) and greater innovation (Chen et al. (2016a) and Chen et al. (2016b)).

Information provided by company employees and disseminated over social media may be useful in understanding a corporation's operating performance and returns (Green et al. (2019), Huang et al. (2020), and Ylinen and Ranta (2021)). For example, Huang et al. (2020) find a positive relationship between Glassdoor's measure of employee confidence and the firm's following two quarters' ROA. 3 Ylinen and Ranta (2021) find that text-based measures of crowdsourced employee reviews are associated with higher ROA and Tobin's Q and Chemmanur et al. (2019) find that when issuing equity, firms with higher employees' online ratings enjoy higher abnormal stock returns at the announcement and better long-run post-SEO operating performance.

Further research suggests that employee satisfaction is related to various measures of firm risk. For example, firms with better employee treatment schemes have lower debt ratios (Bae et al. (2011)), hold more cash (Ghaly et al. (2015)) and are less likely to experience

\footnotetext{
${ }^{3}$ Glassdoor asks employee reviewers to comment on whether they think business will get better, stay the same, or get worse over the next six months.
} 
bankruptcy (Verwijmeren and Derwall (2010)). Guo et al. (2016) find that these companies are less likely to require financial restatements due to unintentional error. Chi and Chen (2021) use Glassdoor data and find that employee ratings and sentiment are negatively correlated with a firm's cost of debt and Bargeron et al. (2015) find that firms with high cultures of trust tend to make smaller acquisitions.

\section{Data and empirical method}

\subsection{Sample and data}

We gather employees'-given satisfaction ratings posted on Glassdoor for Russell 3000 companies over the time period March 13, 2020 to December 31, 2020. We match ratings with Russell 3000 companies by the unique ticker and $\backslash$ or company name. This results in a sample of 1,829 unique companies receiving a total of 220,760 ratings.

The employee satisfaction measure $(E S)$ used in this analysis is employee's 'overall' rating of the company and measured as one (worst) to five (best) which is presented in terms of stars on the website. For firms receiving more than one rating per day, the daily average is used. We gather ratings from the 24 hour period prior to market close, i.e. beginning at 16:00 EST/EDT the prior day until the current day at 16:00 EST/EDT. 4

We further separate ratings by those flagged by Glassdoor as a "COVID-19 review" and those that are not. 5 This results in three separate ES variables: All, which includes all reviews during the sample period $\left(E S_{A l l}\right)$; Non-COVID, which includes all reviews which are not identified as relating to the COVID-19 Pandemic $\left(E S_{n o n-C O V I D}\right)$; and COVID, which includes only the reviews which were identified by Glassdoor as relating to the COVID-19 Pandemic $\left(E S_{C O V I D}\right)$. This resulted in 1116 firms with $E S_{C O V I D}$ reviews during the sample.

Stock prices are obtained from CRSP and daily stock returns for firm $i$ at time $t$ are calculated as the current day's closing price divided by the prior day's closing price minus 1 times 100 and labeled $R_{i t}$. ${ }^{6}$ We further estimate abnormal returns as the difference between daily returns and expected returns $\left(A R_{i t}=R_{i t}-E\left(R_{i t}\right)\right)$. The daily expected return for a stock is calculated as:

$$
E\left(R_{i t}\right)=\hat{\alpha}_{i}+\hat{\beta}_{i} R_{m, t}
$$

Expected Returns, as described by Equation 1, is estimated by the CAPM. $R_{m, t}$ is the market return at time $t$ calculated as a value-weighted portfolio of all US firms with data

\footnotetext{
${ }^{4}$ Reviews received from Friday after 16:00 EST/EDT until Sunday at 16:00 EST/EDT are excluded.

${ }^{5}$ Glassdoor flagged ratings as specifically relevant to the COVID-19 Pandemic's impact by an automated internal algorithm based on text included in the review.

${ }^{6}$ Observations where the absolute value of daily returns is greater than 100 were dropped.
} 
available on CRSP and are listed on either the NYSE, NASDAQ or AMEX. 7 Coefficients are estimated for each stock $i$ using OLS for daily returns over the period January 1, 2018 to March 12, 2020 (prior to start of the COVID-19 Pandemic).

We merge the Glassdoor ratings and company ratings using company tickers and ensure matching using company name. Daily returns are matched to reviews received over the 24 hour period ending at 16:00 EST/EDT as described above. This resulted in a total of 84,762 matched daily returns for $E S_{A l l}$. ES $S_{\text {non-COVID }}$ was matched with 82,455 daily stock returns. While $E S_{C O V I D}$ was matched with 7,141 daily stock returns. Descriptive statistics are presented in Table 1 .

Table 1: Descriptive Statistics

\begin{tabular}{lccccc}
\hline \hline Statistic & $\mathrm{N}$ & Mean & St. Dev. & Min & Max \\
\hline Returns $(R)$ & 84,762 & 0.240 & 3.904 & -60.541 & 60.291 \\
Abnormal Returns $(A R)$ & 84,762 & 0.010 & 3.307 & -53.784 & 60.268 \\
$E S_{\text {All }}$ & 84,762 & 3.675 & 1.118 & 1.000 & 5.000 \\
$E S_{\text {non-COVID }}$ & 82,455 & 3.687 & 1.105 & 1.000 & 5.000 \\
$E S_{\text {COVID }}$ & 7,141 & 3.549 & 1.448 & 1.000 & 5.000 \\
\hline
\end{tabular}

Note: Table 1 shows the descriptive statistics for the Returns, Abnormal Returns and the Glassdoor based ES measure. The first column shows the variable name. The second column shows the number of observations. The third column shows the mean. The fourth column shows the standard deviation. Final two columns show the minimum and maximum.

As shown by Table 1, the mean for $E S_{C O V I D}$ is 3.55 out of 5 and relatively lower than the other two ES measures. With the mean daily $E S_{C O V I D}$ being 3.55 out of 5 while the other two $E S$ measures with a mean of approximately 3.68 out of 5 . Returns had a positive mean, representing an overall rise in stock prices during the sample. Abnormal Returns also had a positive mean relating to stock returns out-performing expected returns.

\section{$2.2 \quad$ Empirical Method}

We estimate two empirical models for stock returns and abnormal returns estimated using OLS. Equation 2 describes the market model, where the dependent variable is stock $i^{\prime} s$ return on day $t\left(R_{i t}\right)$. Included in the model is the Glassdoor average daily rating given on day $t$, the equally weighted return on the market, and the two Fama-French factors introduced in Eugene and Kenneth (1993), SML and HML Eugene and French (1992).

\footnotetext{
${ }^{7}$ This data is obtained from the Kenneth French website.
} 


$$
R_{i t}=\alpha+\beta_{1} E S_{i t}+\beta_{2} R_{m, t}+\beta_{3} S M B_{t}+\beta_{4} H M L_{t}+u_{i t}
$$

In Equation 2, $E S_{i t}$ is the Glassdoor $E S$ measure either $E S_{A l l}, E S_{\text {non-COVID }}$, or $\left(E S_{C O V I D}\right)$ for firm $i . R_{m, t}$ is the market return as described in Equation 1. SMB and HML are the Fama-French factors on day $t$. ${ }^{8} u_{i t}$ is the standard error term.

Equation 3 describes the abnormal returns model, where the dependent variable is the abnormal returns as measured as the difference between returns and expected returns for stock $i$ and day $t\left(A R_{i t}\right)$ as discussed in Equation 1. Other variables are as described in Equation 2.

$$
A R_{i t}=\alpha+\beta_{1} E S_{i t}+\beta_{2} S M B_{t}+\beta_{3} H M L_{t}+u_{i t}
$$

\section{Results}

Table 2 presents the empirical results. The first three columns detail the results for the Returns model (2). While the next three columns detail the results for the Abnormal Returns model (3). Results for the COVID-19 specific ES measure (ESCOVID) are shown in the third and sixth columns. While results for the other ES measures are found in the other columns. Standard errors are clustered by industry and industry fixed effects are included. 9 Industry is identified by using the Fama-French 30 industry SIC code classification. 10

For both models including $E S_{C O V I D}$, we find evidence of a positive and statistically significant relationship between daily stock returns and abnormal returns and COVID-19 related employee satisfaction. While no empirical relationship is found for $E S_{A l l}$ and $E S_{\text {non-COVID }}$ and returns.

The positive coefficient on the $E S$ variable indicates that companies receiving higher employee satisfaction experienced higher daily abnormal returns. The coefficient on $E S_{C O V I D}$ of 0.05 when measuring abnormal returns suggests that a firm receiving a mean daily $E S$ rating of 4 stars vs. 2 stars would be expected to experience a daily abnormal return of $0.1 \%$ higher, all else equal. Considering that the average daily equally weighted return on the market for the study period (March 13 - December 31 2020) is $0.05 \%$, this coefficient is economically as well as statistically significant.

\footnotetext{
${ }^{8}$ The Fama-French factors were obtained from Kenneth French's website. See https://mba.tuck. dartmouth.edu/pages/faculty/ken.french/data_library.html

${ }^{9}$ For robustness, Firm fixed effects were also used. Results are similar and can be provided upon request.

${ }^{10}$ The Fama-French industry SIC code classifications can be found here https://mba.tuck.dartmouth. edu/pages/faculty/ken.french/Data_Library/det_30_ind_port.html
} 
Table 2: Empirical Results: Employee Satisfaction and Returns

\begin{tabular}{|c|c|c|c|c|c|c|}
\hline \multirow[b]{2}{*}{$E S_{A l l}$} & \multicolumn{3}{|c|}{ Returns $(R)$} & \multicolumn{3}{|c|}{ Abnormal Returns $(A R)$} \\
\hline & $\begin{array}{l}-0.003 \\
(0.014)\end{array}$ & & & $\begin{array}{c}-0.002 \\
(0.014)\end{array}$ & & \\
\hline$E S_{\text {non-COVID }}$ & & $\begin{array}{l}-0.006 \\
(0.014)\end{array}$ & & & $\begin{array}{c}-0.004 \\
(0.013)\end{array}$ & \\
\hline$E S_{C O V I D}$ & & & $\begin{array}{l}0.051^{* *} \\
(0.021)\end{array}$ & & & $\begin{array}{l}0.050^{* *} \\
(0.022)\end{array}$ \\
\hline$R_{m}$ & $\begin{array}{c}1.033^{* * *} \\
(0.021)\end{array}$ & $\begin{array}{c}1.033^{* * *} \\
(0.022)\end{array}$ & $\begin{array}{c}1.038^{* * *} \\
(0.034)\end{array}$ & & & \\
\hline SMB & $\begin{array}{c}0.534^{* * *} \\
(0.057)\end{array}$ & $\begin{array}{c}0.519^{* * *} \\
(0.059)\end{array}$ & $\begin{array}{c}0.531^{* * *} \\
(0.090)\end{array}$ & $\begin{array}{c}0.526^{* * *} \\
(0.057)\end{array}$ & $\begin{array}{c}0.511^{* * *} \\
(0.059)\end{array}$ & $\begin{array}{c}0.512^{* * *} \\
(0.087)\end{array}$ \\
\hline HML & $\begin{array}{l}0.255^{* *} \\
(0.113)\end{array}$ & $\begin{array}{l}0.258^{* *} \\
(0.113)\end{array}$ & $\begin{array}{l}0.276^{* *} \\
(0.133)\end{array}$ & $\begin{array}{l}0.252^{* *} \\
(0.115)\end{array}$ & $\begin{array}{l}0.255^{* *} \\
(0.115)\end{array}$ & $\begin{array}{l}0.280^{* *} \\
(0.132)\end{array}$ \\
\hline $\mathrm{N}$ & 84,762 & 82,455 & 7,141 & 84,762 & 82,455 & 7,141 \\
\hline$R^{2}$ & 0.326 & 0.325 & 0.32 & 0.071 & 0.07 & 0.088 \\
\hline
\end{tabular}

Note: Table 2 shows the empirical results. The first three columns show the estimated results from Equation 2 with daily Returns being the dependent variable. The third through six columns show the estimated results from Equation 3 with daily Abnormal Returns being the dependent variable. All coefficients are estimated using OLS. ES $S_{A L L}$ is the employee satisfaction measure as estimated by the Glassdoor reviews for all reviews during the sample period (March 13,2020 - December 31, 2020). E $S_{\text {non-COVID }}$ is all reviews identified as not being related to the COVID-19 Pandemic. While ES COVID is all reviews identified by Glassdoor as specifically relating to the COVID-19 Pandemic. $R_{m}$ is the market returns as estimated as a value weight portfolio of US securities traded on the NYSE, NASDAQ, and AMEX stock exchanges. SMB and HML are the two additional Fama-French factors. Standard errors, shown in parenthesis, are clustered by the Fama-French 30 industries. Industry fixed effects are also used. ${ }^{*} \mathrm{p}<0.1{ }^{* *} \mathrm{p}<0.05$; ${ }^{* * *} \mathrm{p}<0.01$. 
The coefficients on the control variables SMB, HML are consistent for all 6 specifications in size and significance, suggesting that although the number of observations varies by sample, the model is identifying the influence of the control variables SMB, HML, and market return consistently across the samples and specifications.

These results suggest that while overall employee satisfaction is not related to returns, as would be expected by the efficient market hypothesis (EMH), COVID-19 related employee satisfaction is related to both the cross section of returns and abnormal returns. As noted by Baker and Wurgler (2007) limited information leads investors to speculate. Our results suggest that this channel may be valid for explaining stock returns and abnormal returns during the COVID-19 Pandemic.

Employees were the first to experience changes in company operations resulting from the COVID-19 Pandemic and as such provided one of the only new sources of information regarding future profitability. Under the EMH, the new information would be internalized and thus reflected in stock returns. If the new information led investors to speculate, employee satisfaction would be a valid predictor for the cross section of stock returns.

\section{Conclusion}

The COVID-19 Pandemic brought about enormous changes to companies and turmoil for the workforce. Massive layoffs, and for some companies, aggressive hiring sprees, lead to a

labor market that was in flux while US unemployment climbed to the highest level in eighty years. During times of high uncertainty, stock investors may rely on crowdsourced employee reviews as a valuable source of information when making decisions. Employees can offer a unique and valuable perspective to changes in firm operations. Further, research suggests that firms with happier employees may be less risky and therefore better suited to survive external macroeconomic shocks.

Using employee reviews on Glassdoor during the period March 13 - December 31, 2020 we find that those firms receiving higher COVID-19 specific employee reviews experience higher stock returns and abnormal stock returns. We further find that crowdsourced employee satisfaction during this period that do not relate explicitly to the COVID-19 Pandemic are not empirically related to stock returns. This study adds to the body of work being developed using crowdsourced ES data. Future work includes additional event studies measuring abnormal announcement returns for firms with higher verses lower employee-given satisfaction ratings. Further, long-run studies of the relationship between employee satisfaction and firm performance can enhance our understanding of how external shocks affect firms differently. 


\section{References}

Au, S.-Y., Dong, M., and Tremblay, A. (2021). Employee flexibility, exogenous risk, and firm value. Journal of Financial and Quantitative Analysis, 56(3):853-884.

Bae, K.-H., Kang, J.-K., and Wang, J. (2011). Employee treatment and firm leverage: A test of the stakeholder theory of capital structure. Journal of financial economics, 100(1):130153.

Baker, M. and Wurgler, J. (2007). Investor sentiment in the stock market. Journal of economic perspectives, 21(2):129-152.

Bargeron, L., Lehn, K., and Smith, J. (2015). Employee-management trust and m\&a activity. Journal of Corporate Finance, 35:389-406.

Cao, Z. and Rees, W. (2020). Do employee-friendly firms invest more efficiently? evidence from labor investment efficiency. Journal of Corporate Finance, 65:101744.

Chemmanur, T. J., Rajaiya, H., and Sheng, J. (2019). How does online employee ratings affect external firm financing? evidence from glassdoor. Evidence from Glassdoor (December 16, 2019).

Chen, C., Chen, Y., Hsu, P.-H., and Podolski, E. J. (2016a). Be nice to your innovators: Employee treatment and corporate innovation performance. Journal of corporate finance, 39:78-98.

Chen, J., Leung, W. S., and Evans, K. P. (2016b). Are employee-friendly workplaces conducive to innovation? Journal of Corporate Finance, 40:61-79.

Chi, W. and Chen, Y. (2021). Employee satisfaction and the cost of corporate borrowing. Finance Research Letters, 40:101666.

Edmans, A. (2011). Does the stock market fully value intangibles? employee satisfaction and equity prices. Journal of Financial economics, 101(3):621-640.

Eugene, F. and French, K. (1992). The cross-section of expected stock returns. Journal of Finance, 47(2):427-465.

Eugene, F. and Kenneth, F. (1993). Common risk factors in the returns on stocks and bonds. Journal of Financial Economics. 
Faleye, O. and Trahan, E. A. (2011). Labor-friendly corporate practices: Is what is good for employees good for shareholders? Journal of Business Ethics, 101(1):1-27.

Fauver, L., McDonald, M. B., and Taboada, A. G. (2018). Does it pay to treat employees well? international evidence on the value of employee-friendly culture. Journal of Corporate Finance, 50:84-108.

Ghaly, M., Dang, V. A., and Stathopoulos, K. (2015). Cash holdings and employee welfare. Journal of Corporate Finance, 33:53-70.

Green, T. C., Huang, R., Wen, Q., and Zhou, D. (2019). Crowdsourced employer reviews and stock returns. Journal of Financial Economics, 134(1):236-251.

Guo, J., Huang, P., Zhang, Y., and Zhou, N. (2016). The effect of employee treatment policies on internal control weaknesses and financial restatements. The Accounting Review, 91(4):1167-1194.

Huang, K., Li, M., and Markov, S. (2020). What do employees know? evidence from a social media platform. The Accounting Review, 95(2):199-226.

Lins, K. V., Servaes, H., and Tamayo, A. (2017). Social capital, trust, and firm performance: The value of corporate social responsibility during the financial crisis. the Journal of Finance, 72(4):1785-1824.

Verwijmeren, P. and Derwall, J. (2010). Employee well-being, firm leverage, and bankruptcy risk. Journal of Banking \&6 Finance, 34(5):956-964.

Ylinen, M. and Ranta, M. (2021). Employee-friendly corporate culture and firm performance: Evidence from a machine learning approach. Available at SSRN 3813075. 